\title{
Event-related potential correlates of proactive interference in schizophrenic patients and controls
}

\author{
PATRICIA RÖßNER, BRIGITTE ROCKSTROH, RUDOLF COHEN, MICHAEL WAGNER, \\ AND THOMAS ELBERT \\ Department of Psychology, University of Konstanz, Germany
}

\begin{abstract}
Performance and event-related potentials (ERPs) were examined in a proactive interference (PI) task with 15 male schizophrenic patients and 15 matched healthy controls. Within a paired-associate task, 30 pairs of semantically unrelated words (A-B) were presented twice, followed by cued recall, in which the paired-associate B had to be named upon cue A. Subsequently, 50\% of the A-words were paired with new words (A-C) and presented in random order together with 15 novel pairings (D-E). Slower responses and poorer recall of C- than of E-words in the final recall indicated PI in both groups. During acquisition, the paired-associates $(\mathrm{C} / \mathrm{E})$ evoked larger P3 and positive slow wave in controls than in patients. During recall, cues (A/D) evoked a slow wave with predominating anterior negativity in controls and posterior positivity in patients. The group-specific ERP pattern suggests deviant encoding and retrieval processes in schizophrenic individuals.
\end{abstract}

Descriptors: Event-related potentials, P300, Negative slow wave, Schizophrenia, Proactive interference, Inhibition

How associative links are formed and learned in schizophrenia have intrigued scientists since Eugen Bleuler described "loosening of associations" as a constitutive feature of schizophrenic symptomatology in 1911. However, relating this concept to distinct dysfunctional cognitive processes proved to be difficult, particularly to memory processes as conceptualized by cognitive and experimental psychology. One major problem originated from the need to demonstrate differential impairments in schizophrenic patients over and above their general performance deficit (Blanchard \& Neale, 1994; Goldberg, Weinberger, Berman, Pliskin, \& Podd, 1987). Evidence of differential impairment in neuropsychological functions is inconsistent: selective deficits were reported for recall as compared with recognition (Beatty, Jocic, Monson, \& Staton, 1993; Calev, 1984; Goldberg, Weinberger, Pliskin, Berman, \& Podd, 1989; Koh, 1978; McKenna et al., 1990; Saykin et al., 1991), semantic memory (Calev, Venables, \& Monk, 1983), verbal learning and memory (Saykin et al., 1991, 1994), perceptual organization (Knight, 1984), visual-motor processing (Albus et al., 1996; Saykin et al., 1991, 1994), and visual memory (Saykin et al., 1991). Other studies, such as the one by Blanchard and Neale (1994), failed to uncover differential neurocognitive deficits in schizophrenic persons, both on individual tests and for the com-

This research was supported by the Deutsche Forschungsgemeinschaft.

We thank Drs. H. Watzl, P. Werle, and U. Becker for providing diagnoses and psychopathological status of the patient sample, and K. Hönig for assistance in data collection and analysis. We also express our sincere gratitude to Drs. Judith M. Ford and Walton T. Roth, VA Medical Center Palo Alto, CA, for their helpful comments on the manuscript.

Address reprint requests to: Prof. Dr. Brigitte Rockstroh, Fachgruppe Psychologie, Universität Konstanz, P.O.Box D23, D-78457 Konstanz, Germany. E-mail: brigitte.rockstroh@uni-konstanz.de. posite function scores used by Saykin et al. (semantic memory, visual memory, abstraction, language, visual perception, motor ability, and somatosensory capacity).

The notion of "loosening of associations," intrusions, or overinclusion usually implies that competing associations or irrelevant contextual information are not sufficiently inhibited to allow for adaptive responses; this "filter" deficit may lead to the distractibility (Elkins \& Cromwell, 1994) and other attention disorders often described for schizophrenic individuals (Anderson \& Bjork, 1994; Chapman \& Chapman, 1973; Nestor et al., 1992; Zacks \& Hasher, 1994). Experiences from the past interfere with the appropriate appreciation of immediate task demands. Thus, inhibitory processes are often mentioned in the discussion of learning and memory retrieval processes (e.g., Anderson \& Spellman, 1995), and a weakening of inhibitory processes has been assumed to contribute to neuropsychological dysfunctions in schizophrenia. Without referring to an inhibitory nature of the influence of past on future learning, Gray, Felden, Rawlins, Hemsley, and Smith (1991; see also Hemsley, 1993) suggested that a weakening of the influence of previous experiences or memories of past regularities on the control of current perception, "a failure in acute schizophrenics to integrate stored memory of past regularities of perceptual input with ongoing motor programs in the control of current perception" (1991, p. 1) constitutes a neuropsychological dysfunction in schizophrenic persons.

One indicator for the (interfering, inhibitory) effects of prior learning on the acquisition of new information is seen in the phenomenon of proactive interference (PI): PI refers to the reduced or delayed recall of recently learned material subsequent to earlier learning ("when something learned earlier impairs the ability to recall something learned more recently"; Bjork, 1992, p. 283). 
Heightened sensitivity to PI has been reported in patients with frontal lobe lesions and amnesia (Kinsbourne \& Winocur, 1980; Shimamura, 1995; Winocur \& Weiskrantz, 1976) and has been interpreted as a consequence of an impaired spatiotemporal memory that prevents amnesic patients from remembering (Schacter, 1987, p. 24). If PI is related to an inhibitory effect and an inhibitory potential is weakened in schizophrenic individuals, we might expect more errors under interference conditions, that is for the recall of recent material that is similar to material learned earlier, in schizophrenics, which would indicate an increased PI effect. ${ }^{1}$ In nonmedicated, acutely ill schizophrenic individuals, O'Carroll (1995; O'Carroll et al., 1993) demonstrated PI effects similar to depressive and healthy control subjects. ${ }^{2}$ Thus, the significance of PI as another index of weakened inhibition in schizophrenic subjects does not seem to be established.

Insufficient inhibitory processes and less influence of past associations on performance in schizophrenic individuals have also been inferred from findings such as less (than in healthy controls) inhibition of the startle reflex following a prestimulus that is presented between 60 and $250 \mathrm{~ms}$ prior to the startle probe (Braff, Callaway, \& Naylor, 1977; Braff \& Saccuzzo, 1985; Braff et al., 1978), a deficient suppression of the P50-evoked potential component to the second stimulus presented with a stimulus onset asynchrony of less than $500 \mathrm{~ms}$ (Adler, Waldo, Nagamoto, Baker, \& Freedman, 1991), disrupted latent inhibition in acute schizophrenic patients (Baruch, Hemsley, \& Gray, 1988; De la Casa \& Lubow, 1994³ , reduced Kamin blocking effect (Jones, Gray, \& Hemsley, 1992), or reduced negative but increased positive spatial and semantic priming (Beech, Powell, McWilliam, \& Claridge, 1989; McDowd, Filion, Harris, \& Braff, 1993; Salo, Robertson, \& Nordahl, 1996; Spitzer, 1997; Spitzer et al., 1994; Williams, 1996). Furthermore, lower thresholds to transcranial magnetic stimulation in schizophrenic patients were attributed to deficient inhibitory (GABA-mediated) mechanisms (Abarbanel, Lemberg, Yaroslavski, Grisaru, \& Belmaker, 1996).

Event-related potentials (ERPs) may be used to investigate electrocortical correlates of processes involved in paired associate learning and recall, and therefore also in PI. ERPs may thereby provide some insight into mechanisms involved in the PI effect in healthy subjects and in persons with schizophrenia. Apparently, only one study (Uhl et al., 1990) has examined ERPs in a PI task: wordpairs were presented one-by-one with an interstimulus interval of $2.2 \mathrm{~s}$; presentation of both words in the PI condition elicited larger positive deflections (P300) than the "release" condition, in which words with minimal taxonomic similarity were presented; further-

${ }^{1}$ Different terms are used in the discussion of PI, which refer to somewhat controversial processes: inhibition is used to describe active suppression, and interference refers to susceptibility of performance decrements due to automatic or passive processes (Harnishfeger \& Bjorklund, 1994). Inhibition in memory and forgetting suggests explicit memory processes, the definition of PI implicit learning and memory. Proactive interference has also been related to working memory. Furthermore, the PI effect and its variation are related by different authors to a deficit in memory encoding, but also to the effect of the memory trace of subsequent learning and recall.

${ }^{2}$ Several authors reported schizophrenic patients to exhibit less release from PI than normal controls (e.g., Kay, 1982; Randolph, Gold, Carpenter, Goldberg, \& Weinberger, 1992). However, because release from PI refers to a different paradigm than the one used in the present study, this work is not cited in detail here.

${ }^{3}$ Latent inhibition is defined as a decrement in learning performance that results from nonreinforced preexposure of the to-be-conditioned stimulus (Lubow, 1989, 1997). Schizophrenic patients, however, exhibited facilitated learning after preexposure, but only in the acute state. more, an anterior slow negative wave preceding the presentation of the second word in a pair was more pronounced under PI conditions than under release. This ERP study was complemented by measuring regional cerebral blood flow (via single positron emission computed tomography [SPECT]) under the same experimental conditions, which revealed higher flow indices in the right anterior middle frontal region in the PI than in the release condition (Uhl, Podreka, \& Deecke, 1994).

Examining event-related counterparts of encoding and retrieval processes disclosed efficient learning to be associated with positive deflections. Larger P300 and late positive waves ("P5," late positive complex [LPC]) were found during elaborate, intentional semantic encoding (Naumann, 1985) and during acquisition to those items that were better remembered (Donchin \& Fabiani, 1991). Rugg (1995) reported a frontal positivity between 500 and $600 \mathrm{~ms}$ (P560) to covary in amplitude with the correct recognition of items as "old" (i.e., previously seen). A link between positive ERPs and inhibitory processes can be created in that positive ERPs have been associated with a phasic deactivation of neuronal networks (Verleger, 1988) or with a dampening of cortical activity during the transmission of information to long-term memory (Elbert, 1993; Elbert \& Rockstroh, 1987). Thus, we might expect late positive ERPs to covary with performance indicators of PI. On the other hand, Uhl et al. (1990) described a left dorsolateral frontal negative slow wave preceding the second word in an intentional paired associate learning task. Furthermore, Rösler and colleagues (for summary, see Rösler, Heil, \& Röder, 1997) described anterior negative slow waves to be associated with storage and retrieval processes: They were pronounced during the 4-s interval between stimuli, the association of which had to be learned, varying in amplitude with the task demand and varying in scalp distribution with the to-be-associated material (verbal, spatial, color), and these waves were found with similar amplitude and scalp distributions during the retrieval task even days after the learning (Heil, Rösler, $\&$ Hennighausen, 1996). The material-specific topography of these slow negative waves argues against-but does not completely rule out - a contribution of a projection from temporal activity.

The present study examined ERPs in schizophrenic patients and healthy controls in a PI task with the aim to better understand mechanisms of the PI effect. In particular, we wanted to elucidate the impact of inhibitory processes on the PI effect: If PI was related to an inhibitory influence of preceding associations on subsequent learning and recall, and if inhibitory processes were related to positive deflections in the ERP, larger positive slow waves should accompany the PI effect indicated by performance measures. If schizophrenic patients have insufficient inhibitory processes, they should show a reduced PI effect together with reduced positive slow waves.

\section{Methods}

\section{Subjects}

Fifteen male schizophrenic inpatients (mean age $29.6 \pm 5.4$ years) were recruited from the local State Hospital. The diagnoses according to the Diagnostic and Statistical Manual of Mental Disorders (DSM) (American Psychiatric Association, 1994) were based on the answers given in the Present State Examination (PSE, Wing, Cooper, \& Sartorius, 1974), clinical files, and extended personal contact with the patient and was given by the psychiatrist and the psychologist of the research ward. Ten of the 15 patients were diagnosed as paranoid-hallucinatory (DSM IV 295.3), and 5 patients as disorganized or undifferentiated subtype (DSM IV 295.1 
or .9). Duration of illness since the first admission varied between 2 months and 12 years (mean 3 years 9 months), the number of hospital admissions ranged from 1 to 17 (mean $4.5 \pm 4.4$ ). Patients with a schizoaffective disorder or patients with an additional diagnosis of substance dependence were not admitted to the study. Patients were also excluded if they had a neurological disorder or if electroencephalographic (EEG) or computed tomography (CT) abnormalities in the routine examination upon admission were detected. The clinical status during the week of the investigation was evaluated by the Brief Psychiatric Rating Scale (BPRS, Overall \& Gorham, 1962, as modified by Lukoff, Nuechterlein, \& Ventura, 1986). ${ }^{4}$ Individual mean scores varied between 24 and 67 (mean $\pm S D 42.9 \pm 11.9$ ). Patients were given neuroleptic medication, receiving either standard or atypical neuroleptics (mean $213 \pm 154 \mathrm{mg}$ /day chlorpromazine equivalent). Four of the patients received additional anticholinergics. Fifteen healthy male subjects (mean age 29.6 \pm 6.0 years) were matched to the patient group on age and education. Years of education were $11.4 \pm 3$ years in patients and $10.4 \pm 5$ years in controls. The level of intelligence, as assessed by the German Wortschatztest (Schmidt \& Metzler, $1992^{5}$ ) was 101 (raw values $31.8 \pm 6.0$ for the patient group and $31.9 \pm 4.3$ for the control group). Control subjects were asked whether they were currently taking any medication (and if so, what kind of medication) and whether they had ever been treated for neurological or psychiatric disorders. Only subjects who did not take any psychotropic medication and had never been treated for neurological or psychiatric disorders were accepted for the study. Except for one left-handed patient, all subject were right-handed as verified by a modified version of the Edinburgh handedness questionnaire (Oldfield, 1971).

\section{Design and Procedure}

For the paired-associate learning task, high-frequent, concrete German nouns of low associative proximity were selected from respective lists (Hager \& Hasselhorn, 1994; Ruoff, 1981). The pairedassociate paradigm proposed by Postman and Underwood (1973) was modified to allow ERP measurement in the following way (see Figure 1): In the first acquisition phase 30 word pairs (A-B) were presented twice in immediate succession. Subjects were instructed to keep the word pairs in mind. Words were presented visually one at a time, each for $1 \mathrm{~s}$, separated by an interstimulus interval of 2 s. One second prior to each word presentation, a diamond appeared for $300 \mathrm{~ms}$ reminding the subject to fixate and indicating that the next word would be presented (the next word appeared $700 \mathrm{~ms}$ after the offset of the fixation diamond). After this acquisition period, the cued recall was introduced: within each trial, the first word of each pair (A) was presented and subjects were asked to

${ }^{4}$ The expanded BPRS with behavioral anchors (Lukoff et al., 1986) allows the evaluation of the target symptoms on the basis of 24 constructs: somatic concern, anxiety, depression, guilt, hostility, suspiciousness, unusual thought content, grandiosity, hallucinations, disorientation, conceptual disorganization, excitement, motor retardation, blunted affect, tension, mannerisms and posturing, uncooperativeness, emotional withdrawal, suicidality, self-neglect, bizarre behavior, elated mood, motor hyperactivity, and distractibility; the intensity on each construct is rated on a 7-point scale (not observed to extremely severe). Interrater reliability and prognostic validity are considered to be adequate. Means across all 24 constructs are reported as a rough indication of the psychotic condition.

${ }^{5}$ The German Wortschatztest was constructed from the HAWIE, a standard German intelligence test for adults and is used to estimate the premorbid verbal and crystallized intelligence. It consists of 42 lists each comprising 5 pseudowords as distracters and one meaningful, concrete word, which the subject is requested to recognize among the distracters.
DESIGN - PROACTIVE INTERFERENCE

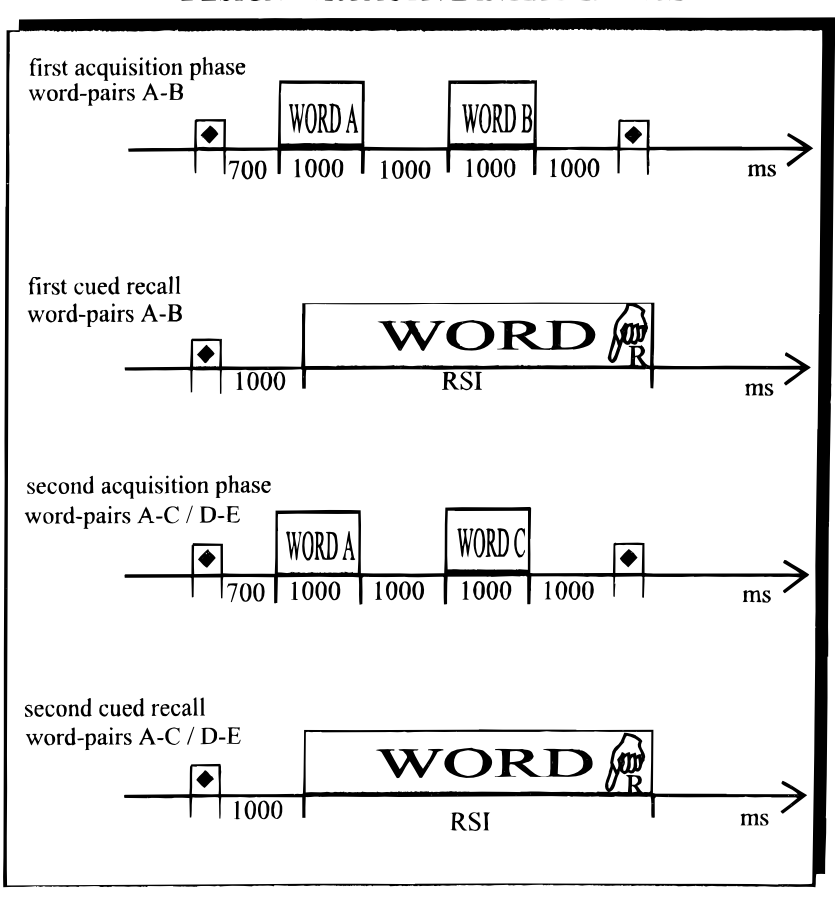

Figure 1. Design: the horizontal axes mark the temporal sequencing for every period. The black diamond is presented at the beginning of each trial for $300 \mathrm{~ms}$ and indicates that the next word will be presented $700 \mathrm{~ms}$ after the disappearance of the black diamond. WORD for the cued recall indicates that the cue word (A or D) is presented and subjects have to indicate by button press ( $\mathrm{R}$ and hand icon) whether or not they recall the associate and are ready to name it. Following the response $\mathrm{R}$ is an interval of $1.5 \mathrm{~s}$ until the beginning of the next trial (RSI, response-stimulus interval).

press one button on a key pad with the index finger as soon as they had recalled the associate (B) and were ready to name it. They were told to press the adjacent button on the key pad with the middle finger if they did not recall the associated item. The cue presentation was terminated by the button press, and the next cue was presented $1.5 \mathrm{~s}$ later (Response-Stimulus Interval, RSI). The cued recall was repeated until $80 \%$ of the paired associates were correctly recalled. Each recall trial started with the presentation of the fixation diamond for $300 \mathrm{~ms}$.

In the second acquisition phase, $50 \%$ of the "A" words used in the first list were paired with new, semantically unrelated words (C) and presented in random order together with 15 new word pairs (D-E). Again, the series was presented twice in immediate succession, followed by a cued recall period, which was repeated between two and five times. (Because a rapid drop in error rates was noted, only the first two repetitions were entered into the data analysis.)

\section{Apparatus and Data Acquisition}

Stimuli were generated by the STIM system (NEUROSCAN) and presented on a 14-inch monitor, which was placed at a distance of about $1.5 \mathrm{~m}$ in front of the subject. A key pad comprising easily manageable microswitches served for motor responses. The key pad was positioned in front of the subject in such a way that the subject could rest his fingers in a relaxed position on the key pad and did not have to turn his eyes away from the monitor for responding. The EEG was recorded with a DC-amplifier (MES, 
Munich) along the midsagittal line ( $\mathrm{Fz}, \mathrm{Cz}, \mathrm{Pz})$, from lateral frontal (F3, F4), central (C3, C4), and parietal (P3, P4) leads, and from both mastoids (A1, A2). FCz, an electrode between $\mathrm{Fz}$ and $\mathrm{Cz}$, served as reference electrode. The vertical and horizontal electrooculograms (EOG) were recorded for the correction of movement artifacts on ERPs (see next paragraph) with electrodes placed about $1 \mathrm{~cm}$ above and below the left eye and on the left and right outer canthi. Nonpolarizable $\mathrm{Ag} / \mathrm{AgCl}$ sintered electrodes (ZAK) were used, Grass EC2 electrolyte served as the conducting agent. The skin under the electrodes was prepared by rubbing with abrasive paste (OMNIPREP). Bandwidth ranged from DC to $30 \mathrm{~Hz}(6$ $\mathrm{dB} /$ octave). For statistical analyses, EEG recordings were converted to mastoid reference (mean of both mastoids) by first converting to average reference and then subtracting the mean of the two mastoid recordings from all channels. All data were digitized at a rate of $100 \mathrm{~Hz}$ and were stored for offline analyses.

\section{Data Reduction and Analysis}

The number of errors (announcing the wrong associate upon cue presentation) during the first two repetitions of the cued recalls served as indicator of performance. Error rates were determined separately for the first (A-B) and the second (A-C, D-E) acquisition period and for the different conditions (A-C vs. D-E). The median reaction time (RT) of correct responses was determined per condition and subject. Due to an error in data acquisition, reaction times of one patient were not stored. Responses with latencies exceeding $5 \mathrm{~s}$ were rejected from data analysis, leading to a rejection of an average of 1.9 trials $(9.0 \%)$ in the patient and an average of 2.2 trials $(9.2 \%)$ in the control group. The EEG recordings were first controlled for slow drifts by an automatic drift correction included in the data acquisition program of the amplifier. The accepted EEG epochs of $1 \mathrm{~s}$ (including 200 ms prestimulus and $800 \mathrm{~ms}$ poststimulus) were corrected for eye movement and blink artifacts according to Elbert, Lutzenberger, Rockstroh, and Birbaumer (1985) and Berg (1986). On the basis of three linear regressions from the calibration data, each EEG channel was corrected with respect to the voltage of three EOG channels, the "vertical" (above-below left eye), the "horizontal" (left-right outer canthi), and the "radial" (mean of the four EOG electrodes-mean of A1 and A2). In addition, all EEG data were inspected visually, and those contaminated by other artifacts (muscle potentials, large drifts, etc.) were rejected. Data of one control subject could not be analyzed because of strong drifts that could not be compensated offline. For the remaining sample, $88.6 \%$ of trials could be analyzed for the patient and $94 \%$ for the control group. Groups did not differ with respect to the percentage of artifact-free trials $(F<1)$.

Inspection of the group averages (see Figures 2 and 3) revealed a distinct sequence of positive and negative deflections, some of which differed between groups and conditions (acquisition and recall period). Scores to describe this sequence of ERPs were determined on the basis of the grand averages depicted in Figures 2 and 3 as follows:

1. Acquisition: The three prominent positive deflections after stimulus onset were determined (for every subject, condition, and electrode for the peak latency at $\mathrm{Pz}$ ) as "P2," that is, peak amplitude between 50 and $200 \mathrm{~ms}$, "P3," that is, peak amplitude between 100 and $300 \mathrm{~ms}$ (labels were chosen for the sake of clarity, although peak latencies did not correspond exactly to 200 or $300 \mathrm{~ms}$ ), and "late positive complex (LPC)," that is, the mean amplitude during the interval $500-800 \mathrm{~ms}$, to account for
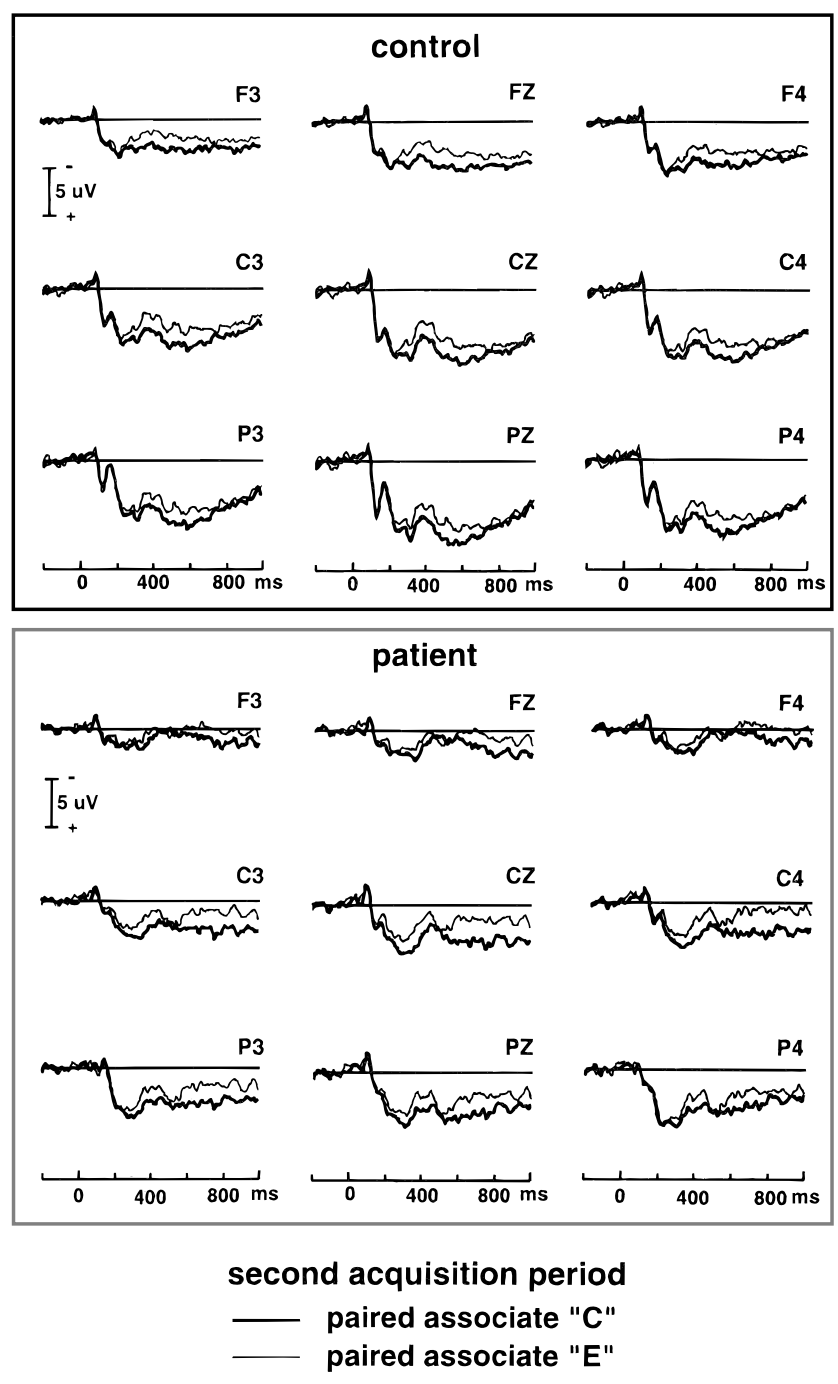

Figure 2. Event-related potentials averaged across subjects and trials for $200 \mathrm{~ms}$ prestimulus and $800 \mathrm{~ms}$ poststimulus during the second acquisition period, separately for controls (top) and schizophrenic patients (bottom), the nine electrodes and averaged separately for the presentation of the paired associates " $\mathrm{C}$ " (following the "A"-words that had been associated with "B"-words in the first acquisition period; thick lines) and "E"-words (that were preceded by " $\mathrm{D}$ "-words, both constituting new words within the item pool; thin lines). Negativity up.

the subsequent broad positive deflection. In a next step, the least positive point between P2 and P3 was subtracted from the average of P2 and P3 amplitudes to describe the "N2," and the least positive point between P3 and LPC was subtracted from the average of P3 and LPC to describe the transient reduction in positivity called "N4." Because Figure 2 suggests that patients did not exhibit the sequence of P2-N2-P3 as clearly as controls, the number of subjects who exhibited this sequence was determined for each group and group differences compared by $\chi^{2}$-test.

2. Recall: As the sequence of P2-N2-P3 was not obvious in the recall period, only the $\mathrm{P} 3$ was determined in the same way as positive maximum in the latency range of $100-300 \mathrm{~ms}$. Furthermore, the mean amplitude during the interval 100-300 ms 

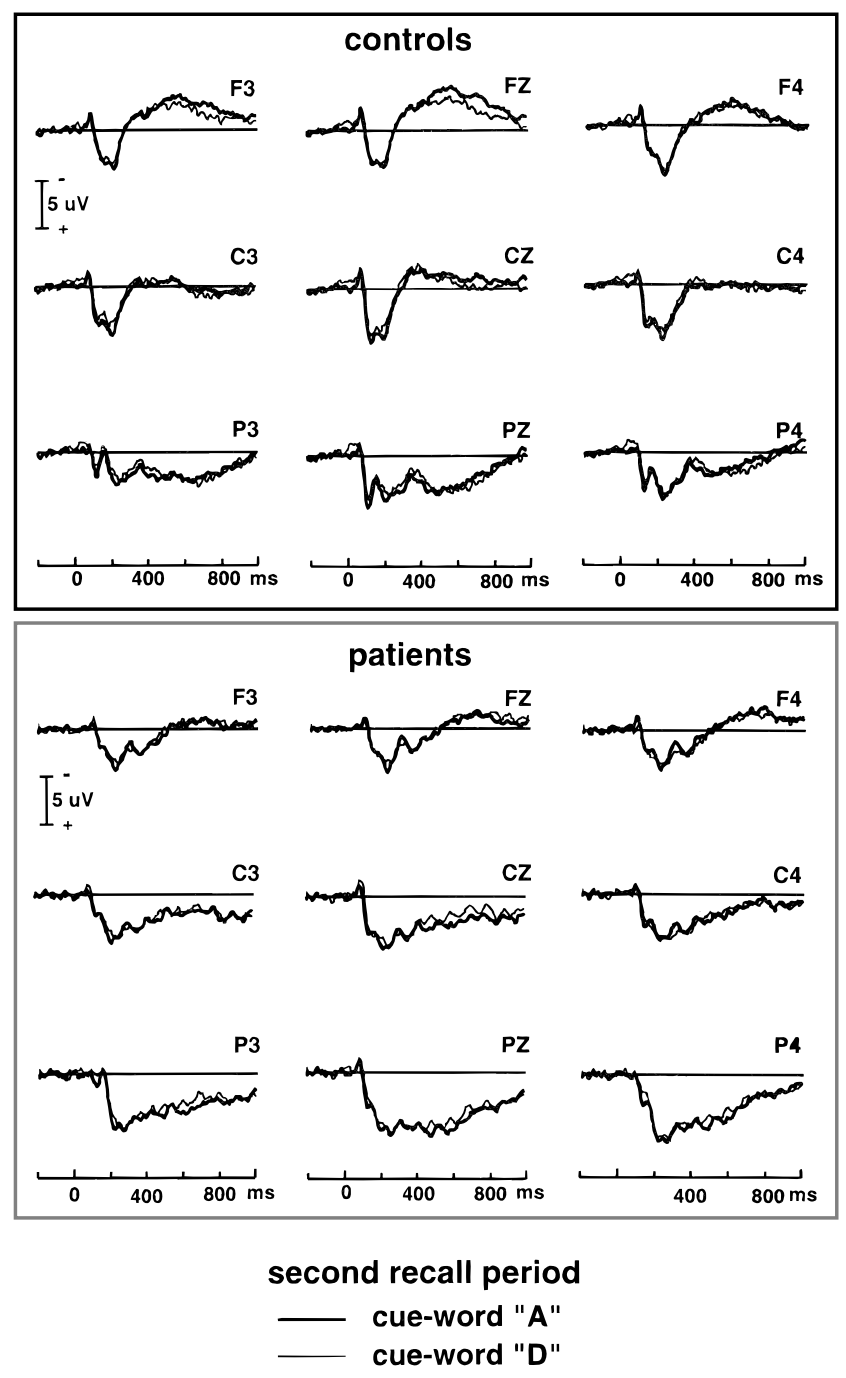

Figure 3. Event-related potentials averaged across subjects and trials for $200 \mathrm{~ms}$ prestimulus and $800 \mathrm{~ms}$ poststimulus during the second recall period, separately for controls (top) and schizophrenic patients (bottom), the nine electrodes and averaged separately the presentation of the cuewords " $\mathrm{A}$ " (which asked for the recall of the paired-associate " $\mathrm{C}$ "; thick lines) and cue-words "D" (which asked for the recall of the pairedassociate "E"; thin lines).

was determined to account for the somewhat broader early positive deflection. The subsequent slow wave (SW) with obvious group-specific topography was described as mean amplitude between 400 and $800 \mathrm{~ms}$.

For performance and ERP indices, differences between groups and conditions were evaluated by means of analyses of variance (ANOVA) with the between-subject factor Group (schizophrenic patients vs. healthy controls) and the within-subject factor Condition (responses to the words $\mathrm{C}$ or $\mathrm{E}$ on acquisition, responses to the cue words A or D on recall trials). For ERP scores, the withinsubject factors Laterality (comparing left-, midline, and righthemispheric recordings), and the Gradient (comparing frontal, central, and parietal recordings) were added. Because the main focus of the present report was on the PI effect, the crucial com-
Table 1. Number of Errors and Reaction Time (RT) Across Groups and Conditions

\begin{tabular}{lccccc}
\hline \hline & \multicolumn{2}{c}{ Errors } & & \multicolumn{2}{c}{ Median RT } \\
\cline { 2 - 3 } \cline { 5 - 6 } Errors & A-C & D-E & & A-C & D-E \\
\hline Patients & $6.96 \pm 0.88$ & $6.00 \pm 0.96$ & & $2,288 \pm 225$ & $1,733 \pm 147$ \\
Controls & $5.13 \pm 0.82$ & $4.57 \pm 0.78$ & & $1,833 \pm 149$ & $1,487 \pm 129$
\end{tabular}

Number of errors out of 15 trials. RT was median across trials for each subject between presentation of cue-letter [A or D] and button press indicating readiness for response $[\mathrm{B}, \mathrm{C}$, or $\mathrm{E}]$ (in $\mathrm{ms}$ ) averaged separately for groups and conditions $(\mathrm{A}-\mathrm{C}, \mathrm{D}-\mathrm{E})$; means and standard errors are given.

parison concerned A-C/D-E pairs in the second acquisition and second recall periods. A comparison with ERPs during the first acquisition/recall periods (A-B) would have been affected by novelty, orienting, or habituation effects. Therefore, effects for the first acquisition/recall period will not be reported here. All $p$ values were determined after adjusting the degrees of freedom with the Greenhouse-Geisser-Epsilon. Epsilon values for degrees of freedom with numerator exceeding 1 will be added in the text. Post hoc comparisons were accomplished by ANOVAs on subsets of data or planned mean comparisons. Means \pm standard errors are presented.

\section{Results}

\section{Performance}

Table 1 summarizes the mean number of errors and the group mean of median RTs (in ms) during the first two recall periods for those paired associates that should indicate the PI effect (A-C, D-E). The scatterplot in Figure 4 illustrates the distribution of PI effects (see figure legend for explanation) among the two groups. As indicated by Figure 4, patients and controls exhibited similar PI effects with increased error rates and reaction times when recalling the asso-

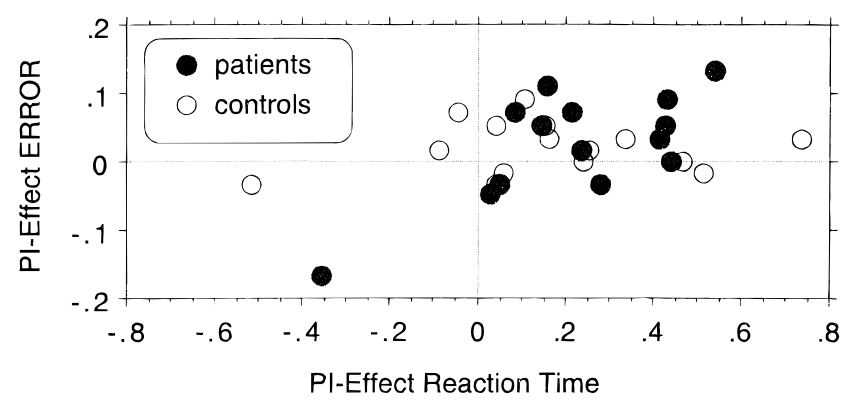

Figure 4. Distribution of the proactive interference (PI) effect on performance for every subject. The PI effects are calculated for errors (ordinate) and median reaction time (abscissa) as difference of performance between the paired associates A-C minus D-E, relative to the total number of errors and the average response latency of the two conditions. Filled circles: schizophrenic patients, open circles: control subjects. The right upper quadrant contains more erroneous and slower responses to recall "C"-associates following "A"-cues than "E"-associates following "D"-cues, indicating PI. With few exceptions, subjects of both groups exhibit the PI effect in one or both performance measures. 
ciates (A-) "C" relative to the associates (D-) "E". The one patient and the one control subject demonstrating the opposite of the PI effect showed high error rates already for the acquisition/recall of the A-B pairs, so presumably they did not learn the task from the beginning. If these subjects are excluded from the statistical analyses, the relative PI effects (relative to the total number of errors or response latency, respectively) were confirmed by $t$ tests for both groups (\% errors, patients: $t[13]=2.4, p<.05$; controls: $t[13]=$ 2.6, $p<.05$; \% RT: patients: $t[13]=3.4, p<.01$; controls: $t[13]=3.4, p<.01)$. Groups did not differ with respect to these PI effects $(F<1)$.

ANOVAs with the raw data confirmed these results: Groups did not differ significantly in their overall error rates or in the latency to the button press, indicating readiness to announce the paired associate ("B", "C" or "E"; $F<1$ ). Both groups recalled more items correctly during the second than during the first presentation of the list, $F(1,26)=40.6, p<.01)$. Both groups made more errors, when they had to recall "C"-words compared to "E"-words, $F(1,26)=10.7, p<.01$, and both groups were also significantly slower when recalling "C"-words $(2051 \pm 138 \mathrm{~ms})$ than " $\mathrm{E}$ "words $(1605 \pm 99 \mathrm{~ms} ; F[1,25]=29.3, p<.01)$. A slightly more pronounced slowing in the patient group (by $555 \mathrm{~ms}$ ) than in the control group $(345 \mathrm{~ms})$ did not reach significance.

\section{Event-Related Potentials}

Figure 2 illustrates the ERPs evoked by the second word in the pair ("C" or "E"), averaged separately for groups and electrodes for the second acquisition epoch.

Although all subjects developed a positive deflection in the P3-latency range, 11 of 14 controls and 11 of 15 patients displayed the sequence of P2-N2-P3 in response to both associates, "C" and "E." For those subjects who exhibited the P2-N2-P3 sequence, the P2 with posterior central and right-hemispheric dominance, Gradient $\times$ Laterality, $F(4,76)=7.0, p<.01, \epsilon=0.4 ; F(2,36)=8.3$, $\epsilon=0.6$, and 16.9, $\epsilon=0.7, p<.01$ for the main effects, was smaller in amplitude in patients than in controls, $F(1,19)=5.9, p<.05$. Corresponding to the impression from Fig. 2, the P2 did not differ between conditions.

The P3 showed a similar scalp distribution being pronounced over posterior, Gradient, $F(2,54)=22.6, \epsilon=0.65, p<.01$, and over the central and right-hemispheric areas, Laterality, $F(2,54)=$ 18.7, $\epsilon=0.98, p<.01$. This positive deflection, too, was less pronounced in patients than in controls, $F(1,27)=4.0, p=.05$. Although Figure 2 suggests that the presentation of " $\mathrm{C}$ "-words (that had to be associated with the preceding "A"-words) evoked larger P3 than the presentation of "E"-words, the effect approached significance only for the peak amplitude, $F(1,27)=3.2, p<.1$. Patients showed a smaller central-to-left gradient in patients than in controls, Group $\times$ Laterality, $F(2,54)=3.3, p<.05$.

For the LPC, a similar pattern of results was confirmed as described for the P3: the LPC with posterior and right-central predominance, Laterality $\times$ Gradient, $F(4,112)=11.8, \epsilon=0.7$, $p<.01 ; F(2,56)=45.9, \epsilon=0.99$, and 39.8, $\epsilon=0.6, p<.01$ for the main effects, was smaller in patients than in controls, $F(1,28)=18.3, p<.01$. In contrast to the $\mathrm{P} 3$, the more pronounced positivity following $\mathrm{C}$ - compared with E-words was significant for the LPC, $F(1,28)=27.3, p<.01$. The difference between conditions was more pronounced at centroparietal recordings, Condition $\times$ Gradient, $F(2,56)=27.1, \epsilon=0.7, p<$ .01 , but interestingly also over the left hemisphere, Condition $\times$ Laterality, $F(2,56)=4.1, \epsilon=0.7, p<.01$; Conditions $\times$ Laterality $\times$ Gradient, $F(4,112)=17.2, \epsilon=0.4, p<.01$. Differ- ences in LPC amplitudes between groups were more pronounced at the locations of amplitude maxima, that is, over central and right-hemispheric areas, Groups $\times$ Laterality, $F(2,56)=8.6$, $p<.01$.

The transient reduction in positivity between $\mathrm{P} 2$ and $\mathrm{P} 3$, called $\mathrm{N} 2$, was most pronounced at $\mathrm{Pz}$ and $\mathrm{Cz}$, and slightly larger over the right than over the left hemisphere, Gradient $\times$ Laterality, $F(4,72)=4.7, \epsilon=0.6, p<.05 ; F(2,36)=13.9, \epsilon=0.6, p<$ .01 , for the main effect Gradient. As indicated by Figure 2, the $\mathrm{N} 2$ was pronounced at $\mathrm{Pz}$ in controls but not in patients, whereas $\mathrm{N} 2$ did not differ between groups at $\mathrm{Cz}$; if only the midline recordings were considered, this group-specific scalp distribution was confirmed as a tendency by an interaction, Group $\times$ Gradient, $F(2,36)=3.4, p<.1$.

The transient relative reduction in positivity between P3 and LPC, called N4, was the same in both groups and in response to both associates. Following the scalp distribution of the P3, the "N4" was larger at parietal and larger at central and right-hemispheric locations, Gradient $\times$ Laterality, $F(4,108)=9.7, \epsilon=0.7, p<.01$; $F(2,54)=29.9, \epsilon=0.66$, and 7.7, $\epsilon=0.8, p<.01$ for the main effects. An interaction Group $\times$ Gradient, $F(2,54)=4.2, p<.05$, indicated a pronounced frontoparietal gradient of the N4 in patients compared with controls. Finally, the difference between the transient reduction in positivity following "C"-words and "E"words was smallest at frontal and most pronounced at right centroparietal leads, Condition $\times$ Laterality $\times$ Gradient, $F(4,108)=$ 7.1, $\epsilon=0.56, p<.01$; Condition $\times$ Gradient, $F(2,54)=5.0, \epsilon=$ $0.7, p<.01$.

Figure 3 illustrates the ERPs during the second recall in response to the cue-words "A" and "D," to which the recall of words "C" or "E" was required. In both groups, the presentation of both cues induced a positive deflection in the latency range of 100-300 ms with right-hemispheric, posterior predominance. For the mean amplitude between $100-300 \mathrm{~ms}$, Gradient $\times$ Laterality, $F(4,112)=10.6$, $\epsilon=0.62, p<.01$; Gradient, $F(2,56)=11.1, \epsilon=0.6, p<.01 ;$ Laterality, $F(2,56)=14.8, \epsilon=0.87, p<.01$; for the peak amplitude in this latency range: Gradient $\times$ Laterality, $F(4,112)=4.9, \epsilon=$ $0.5, p<.01$; Gradient, $F(2,56)=29.8, \epsilon=0.6, p<.01$; Laterality, $F(2,56)=19.7, \epsilon=0.9, p<.01$. The positivity between $100-300$ ms was larger in patients than controls at $\mathrm{Pz}$ and $\mathrm{P} 4$, but larger in controls than in patients at $\mathrm{F} 4$ and $\mathrm{C} 4$, giving rise to the interaction, Group $\times$ Gradient $\times$ Laterality, $F(4,112)=4.1, p<.05$; for the peak amplitude, the interaction fell short of significance with $F(4,112)=2.6, p<.1$. In both groups, the positive deflection tended to be more pronounced following the cue "A" (requiring the recall of the "inhibited" associate " $C$ ") than following the cue " $D$," $F(1,28)=3.2, p<.1$; n.s. for the peak amplitude.

As evident from Figure 3, the early positive deflection is followed by a slow wave extending up to the end of the recording epoch characterized by a anterior (negative)-posterior (positive) gradient. The negative slow wave (nSW) was more pronounced in controls, whereas the centroparietal positivity (LPC) prevailed in patients. This group-specific ERP pattern was verified by significant interactions of Group $\times$ Gradient $\times$ Laterality, $F(4,112)=$ $2.9, p<.05$, whereas the anterior-posterior gradient of the component, particularly pronounced at the midline, was indicated by the main effect Gradient, $F(2,56)=28.0, \epsilon=0.5, p<.01$, and the interaction Gradient $\times$ Laterality, $F(4,112)=7.9, \epsilon=0.6, p<.01$.

Because Figures 2 and 3 suggested that the LPC in patients during recall exceeded the LPC in controls during acquisition, this group-specific ERP pattern was evaluated in an additional ANOVA comprising the two periods (acquisition, recall) as a factor. Sig- 
nificant interactions of Group $\times$ Period supported the larger P3 (peak amplitude) and larger LPC (mean amplitude) in patients during recall, $F(1,26)=8.7, p<.01$ for the $\mathrm{P} 3$, and $F(1,28)=$ $21.0, p<.01$ for the LPC. Post hoc $t$ tests, however, did not confirm that the LPC evoked in patients by the cue words exceeded the LPC evoked in controls during encoding of the associative "C." The LPC was always larger following the associative "C" than following the cue "A," for patients at Pz, $t(14)=5.6, p<$ .01 ; for controls $t(14)=3.3, p<.01$; the respective values for the comparison of associative "E" and cue-word "D" did not reach significance in patients, but only in controls, $t(14)=7.1, p<.01$.

\section{Discussion}

Three results of the present study merit particular attention: (a) Performance measures demonstrated the interference effect in both groups. The design proved adequate to induce the PI effect, that is, more errors and slower responding, whenever paired associates had to be recalled following the learning of word pairs including identical cues. However, patients in the present study did not show hypo- or hypersensitivity to interference, as found in amnesic patients and as expected for schizophrenic patients. The present result is in line with those reported earlier (O'Carroll, 1995; O'Carroll et al., 1993) and helps to clarify the sensitivity of persons with schizophrenia to inhibitory or interfering processes during pairedassociate learning.

Proactive interference was not increased in the present sample of chronic, medicated, partially recovered schizophrenic subjects, nor in the nonmedicated, acutely ill schizophrenic subjects examined by O'Carroll and co-workers. On the other hand, patients were generally slower to respond and made more errors, which is in line with the frequently reported findings and might suggest a general impairment. The lack of a differential effect does not seem to be due to the fact that patients were in a nonacute state at the time of the experiment, because an unimpaired PI effect was found in acutely ill schizophrenic subjects by O'Carroll, and because neuropsychological deficits were often reported to be independent of the psychopathological state or neuroleptic treatment (e.g., McKenna et al., 1990; Saykin et al., 1991, 1994).

(b) To our knowledge, only Uhl et al. (1990) have examined ERP counterparts of PI in a paired-associate task (slightly different from the one implemented in the present study). In the present study, the effect of PI on (poorer) performance was accompanied by larger positive ERPs (P3 and LPC) during the encoding of the interference-prone associates " $\mathrm{C}$ " compared with the new paired associates (D-E). Following our model relating positive ERPs to a reduction in excitability/excitation (Elbert, 1993; Elbert \& Rockstroh, 1987), the present results suggest that positive ERPs constitute the electrocortical correlate of PI. It seems important to notice that this finding was true for healthy subjects as well as for schizophrenic patients. Although schizophrenic patients displayed significantly smaller amplitudes of all positive ERP components than controls, no differential effect of interference was confirmed. In this respect, the present results do not strengthen the assumption of reduced inhibitory processes in schizophrenic individuals.

The larger positivity accompanying the encoding of interfered associates is in contrast to the often reported correspondence of larger P300 and better retrieval (Donchin \& Fabiani, 1991; Rugg, 1995). The reduced positivity in schizophrenic subjects may be interpreted as a sign of deficient encoding, as assumed by Gray et al. (1991). However, such a deficit obviously did not affect the interference effect.
The present results also differ from those of Uhl et al. (1990) and Rösler et al. (1997), who reported anterior nSWs to correspond with memory encoding (Rösler et al., 1997) and PI (Uhl et al., 1990). To what extent the differences in the experimental designs are responsible for the differences in the patterns of results, can only be addressed by further experiments. Recent studies using functional imaging techniques (Cabeza et al., 1997; Gabrieli, Brewer, Desmond, \& Glover, 1997; see also Tulving, Kapur, Craik, Moscovitch, \& Houle, 1994; Wheeler, Stuss, \& Tulving, 1997) suggest distinguishing between brain systems mediating different aspects of memory encoding and retrieval: For instance, Gabrieli et al. (1997) found encoding of pictures to be associated with an activation in the parahippocampal cortex, and retrieval to be associated with activation in the anterior medial temporal lobe. Wheeler et al. (1997) reported a left prefrontal localization of episodic encoding and a right prefrontal localization for episodic retrieval; Cabeza et al. (1997) distinguished recognition and recall on the basis of higher activation in the right inferior parietal cortex for the former and higher cerebrofrontal activation for the latter. Only studies combining imaging and ERP recording would allow a determination of whether these findings indicate that encoding and memory processes show up in the scalp distribution of ERP counterparts of the different processes.

(c) An intriguing finding concerns the group-specific ERP pattern during recall: Whereas smaller than normal P300 are usually reported for schizophrenic patients (for review, see, e.g., Cohen, 1991; Pritchard, 1986) the present design elicited larger positive SWs in patients than in controls, but under conditions not comparable to the oddball task or designs, in which smaller than normal P300 have been reported for schizophrenics. On the other hand, Roth, Goodale, and Pfefferbaum (1991) found P300 of normal size but longer latencies in schizophrenic subjects in response to auditory stimuli separated by interstimulus intervals longer than $12 \mathrm{~s}$, and Pfefferbaum, Ford, White, and Roth (1989) and Ford et al. (1994) reported only slightly reduced P300 amplitudes in patients in response to visual (but not auditory) stimuli, which were independent from medication and clinical improvement. The variation of positive deflections in schizophrenic patients across studies could be considered to argue against a general, schizophrenia-specific dampening of event-related activity. The patient group in the present study displayed smaller P300 amplitude during acquisition and larger positive SWs during retrieval. This finding suggests that the larger positivity should be attributed to specific (cognitive) conditions rather than to the state of the patient.

Patients did not demonstrate the anterior nSW that was prominent in controls. This component has been related to memory search processes (Rösler et al., 1997). The group- and conditionspecific pattern suggests several possibilities, which cannot be verified with our current data: One possibility is that the schizophrenic patients had a deficit in memory search processes. This deficit might have been indicated by the lack of the anterior $\mathrm{nSW}$ and might have induced compensatory activation indicated by a pronounced posterior positivity. Another possibility is that the schizophrenic patients, for whom a general loosening of associations is assumed to be a crucial pathological feature, were impaired during the acquisition of the paired associates. This deficit might have been indicated by the smaller P3 and LPC during acquisition. As a consequence of impaired formation of distinct, critical associations, a more intense inhibition of various, alternative associations may have become necessary, whenever the critical association had to be recalled, this inhibition showing up in the larger positive SW during recall. Future studies are necessary to clarify whether the 
presently observed group-specific ERP pattern during recall of paired associates indicates a specific deficit or characteristic of association formation in schizophrenia or has to be interpreted as (compensatory) consequence of a general deficit in memory encoding and/or general performance decrement.

Finally, a distinct pattern of ERPs was elicited by the present design. Encoding was characterized by a sequence of positive and negative deflections, which was particularly prominent over centroparietal areas. A similar pattern of ERP components was recently shown by Rugg, Mark, Gilchrist, and Roberts (1997) in young subjects in response to the first and repeated presentation of words. Because interference affected only slightly the earlier (P3) and mainly the later (LPC, SW) components in the present task, we might consider the distinct sequence of ERP components up to 400-500 ms as correlates of processes typical for encoding and retrieval. The similarity of the present ERP pattern to the one described by Rugg et al. (1997) also suggests a relationship to the processing of word stimuli, or to the processing of stimuli presented for the first time.

It is tempting to adopt the explanations of negative components, such as the N2 and the N4, provided by other authors for a discussion of the meaning of the negative peaks, $\mathrm{N} 2$ and N4, in the present study. A N2 with posterior predominance contralateral to the position of the target (therefore called N2pc) has been observed by Wagner (1997, unpublished observations) following the change of the target position in a spatial priming paradigm, or by Eimer $(1996 a, b)$ in visual discrimination tasks in response to a switch in target position. According to Eimer, the N2pc indicates attention for the selection of task-relevant stimuli. Although the designs and tasks can clearly differ, we might consider attention selection of the to-be-learned paired associate as a process contributing to the $\mathrm{N} 2$ in the present study. Furthermore, inspection of the averaged ERPs in response to "A"-words during the first and second acquisition periods indicated the occurrence of the $\mathrm{N} 2$ in response to the first associate (A) as well. If the $\mathrm{N} 2$ observed in the present study could be compared with the $\mathrm{N} 2 \mathrm{pc}$, the respective process of spatial attention does not seem to be impaired in schizophrenic patients. Smaller N2 amplitudes and less asymmetry (left-larger-than-righthemispheric) in schizophrenic patients compared with controls have been reported recently in a word recognition task by Kayser et al. (1997). It remains to be clarified whether the smaller parietal N2 in the present patient sample might also be related to atypical word processing.

Rugg, Doyle, and Holdstock (1994; Rugg \& Doyle, 1994) found that repeated high-frequency words modulated a temporally limited region of the ERP waveform, which centered on a negativegoing component that peaked around $400 \mathrm{~ms}$ poststimulus. Rugg associated this component with the N400, because "an important factor controlling the amplitude of the N400 is the ease with which attributes of the evoking stimulus can be integrated or associated with the context in which it is presented" (Rugg et al., 1994, p. 447). The "contextual integration hypothesis" may hold for the first presentation of associates (such as $\mathrm{C}$ and $\mathrm{E}$ words) in the present design. Rugg et al. (1994) did not find differences in the positive deflection, which followed the $\mathrm{N} 4$ and which became larger in amplitude with item repetition, between different types of repetitions, one being similar to the present A-C pairing. Thus, Rugg et al. did not find an interference effect, which may, however, be due to the different task (lexical decision, target selection). The present finding of the "N4" being similar in response to interference and control conditions and being similar in both groups suggest that the process of context integration is not impaired in schizophrenics.

In sum, the present study demonstrated electrocortical counterparts of encoding and recall in a proactive interference task. The group-specific ERP pattern evoked by the cue words during recall suggests (a) that positivity is not generally reduced in schizophrenic individuals under all circumstances, and (b) that future studies should focus on schizophrenic deficits in encoding (with compensatory impact on recall) or recall (dysfunctional memory search).

\section{REFERENCES}

American Psychiatric Association. (1994). Diagnostic and statistical manual of mental disorders (4th ed.). Washington, DC: Author.

Abarbanel, J. M., Lemberg, T., Yaroslavski, U., Grisaru, N., \& Belmaker, R. H. (1996). Electrophysiological responses to transcranial magnetic stimulation in depression and schizophrenia. Biological Psychiatry, 40 $148-150$.

Adler, L. E., Waldo, M. C., Nagamoto, H., Baker, N., \& Freedman, R. (1991). Ten years of studies on P50 sensory gating: An integration of human and animal studies. Psychophysiology, 28, 2.

Albus, M., Hubmann, W., Ehrenberg, Ch., Forcht, U., Mohr, F., Sobizack, N., Wahlheim, C., \& Hecht, S. (1996). Neuropsychological impairment in first-episode and chronic schizophrenic patients. European Archives of Psychiatry and Clinical Neuroscience, 246, 249-255.

Anderson, M. C., \& Bjork, R. A. (1994). Mechanisms of inhibition in long-term memory: A new taxonomy. In D. Dagenbach \& T. H. Carr (Eds.), Inhibition processes in attention, memory and language (pp. 265-325). New York: Academic Press.

Anderson, M. C., \& Spellman, B. A. (1995). On the status of inhibitory mechanisms in cognition: Memory retrieval as a model case. Psychological Reviews, 102, 68-100.

Baruch, L., Hemsley, D. R., \& Gray, J. A. (1988). Differential performance of acute and chronic schizophrenics in a latent inhibition task. The Journal of Nervous and Mental Disease, 176, 598-606.

Beatty, W. W., Jocic, Z., Monson, N., \& Staton, R. D. (1993). Memory and frontal lobe dysfunction in schizophrenia and schizoaffective disorder. The Journal of Nervous and Mental Disease, 181, 448-453.

Beech, A., Powell, T., McWilliam, J., \& Claridge, G. (1989). Evidence of reduced "cognitive inhibition" in schizophrenia. British Journal of Clinical Psychology, 28, 109-116.

Berg, P. (1986). The residual after correcting event-related potentials for blink artifacts. Psychophysiology, 23, 354-364.

Blanchard, J. J., \& Neale, J. M. (1994). The neuropsychological signature of schizophrenia: Generalized or differential deficit? American Journal of Psychiatry, 151, 40-48.

Bleuler, E. (1911). Dementia Praecox und die Gruppe der Schizophrenien [The group of schizophrenias]. In G. Aschaffenburg (Ed.), Handbuch der Psychiatrie (pp. 1-420). Leipzig: Deuticke.

Bjork, R. A. (1992). Interference and forgetting. In L. R. Squire (Ed.), Encyclopedia of learning and memory (pp. 283-288). New York: Macmillan.

Braff, D. L., Callaway, E., \& Naylor, H. (1977). Very short-term memory dysfunction in schizophrenia: Defective short time constant information processing in schizophrenia. Archives of General Psychiatry, 34, 25-30.

Braff, D. L., \& Saccuzzo, D. P. (1985). The time course of information processing deficits in schizophrenia. American Journal of Psychiatry, 142,170174

Braff, D. L., Stone, C., Callaway, E., Geyer, M. A., Glick, I. D., \& Bali, L. (1978). Prestimulus effects on human startle reflex in normals and schizophrenics. Psychophysiology, 14, 339-343.

Cabeza, R., Kapur, S., Craik, F., McIntosh, A., Houle, S., \& Tulving, E (1997). Functional neuroanatomy of recall and recognition: A PET study of episodic memory. Journal of Cognitive Neuroscience, 9, 254265 . 
Calev, A. (1984). Recall and recognition in chronic nondemented schizophrenics. Journal of Abnormal Psychology, 93, 172-177.

Calev, A., Venables, P. H., \& Monk, A. F. (1983). Evidence for distinct verbal memory pathologies in severely and mildly disturbed schizophrenics. Schizophrenia Bulletin, 9, 247.

Chapman, L. J., \& Chapman, J. P. (1973). Disordered thought in schizophrenia. New York: Appleton-Century-Crofts.

Cohen, R. (1991). Event-related potentials and cognitive dysfunctions in schizophrenia. In H. Häfner, \& W. F. Gattaz (Eds.), Search for the causes of schizophrenia (pp. 342-360). Heidelberg: Springer-Verlag.

De la Casa, L. G., \& Lubow, R. E. (1994). Memory for attented and nominally nonattended stimuli in low and high psychotic-prone normal subjects: The effects of test-anticipation. Personality and Individual Differences, 17, 783-789.

Donchin, E., \& Fabiani, M. (1991). The use of event-related brain potentials in the study of memory: Is P300 a measure of event distinctiveness? In J. R. Jennings, \& M. G. H. Coles (Eds.), Handbook of cognitive psychophysiology: Central and autonomic system approaches (pp. 471498). Chichester, UK: Wiley.

Eimer, M. (1996a). The N2pc component as an indicator of attentional selectivity. Electroencephalography and Clinical Neurophysiology, 99, 225-234.

Eimer, M. (1996b). ERP modulation indicate the selective processing of visual stimuli as a result of transient and sustained spatial attention. Psychophysiology, 33, 13-21.

Elbert, T. (1993). Slow cortical potentials reflect the regulation of cortical excitability. In W. McCallum \& H. Curry (Eds.), Slow potential changes in the human brain (pp. 235-252). New York: Plenum Press.

Elbert, T., Lutzenberger, W., Rockstroh, B., \& Birbaumer, N. (1985). Removal of ocular artifacts from the EEG-A biophysical approach to the EOG. Electroencephalography and Clinical Neurophysiology, 60, 455463.

Elbert, T., \& Rockstroh, B. (1987). Threshold regulation-A key to the understanding of the combined dynamics of EEG and event-related potentials. Journal of Psychophysiology, 4, 317-333.

Elkins, I. J., \& Cromwell, R. Z. (1994). Priming effects in schizophrenia: Associative interference and facilitation as a function of visual context. Journal of Abnormal Psychology, 103, 791-800.

Ford, J. M., White, P. M., Csernansky, J. G., Faustman, W. O., Roth, W. T., \& Pfefferbaum, A. (1994). ERPs in schizophrenia: Effects of antipsychotic medication. Biological Psychiatry, 36, 153-170.

Gabrieli, J. D., Brewer, J. B., Desmond, J. E., \& Glover, G. H. (1997). Separate neural bases of two fundamental memory processes in the human medial temporal lobe. Science, 276, 264-266.

Goldberg, T. E., Weinberger, R. D., Berman, K. F., Pliskin, N. H., \& Podd, M. H. (1987). Further evidence for dementia of the prefrontal type in schizophrenia? Archives of General Psychiatry, 44, 1043-1051.

Goldberg, T. E., Weinberger, R. D., Pliskin, N. H., Berman, K. F., \& Podd, M. H. (1989). Recall memory deficit in schizophrenia-A possible manifestation of prefrontal dysfunction. Schizophrenia Research, 2, 251-257.

Gray, J., Feldon, J., Rawlins, J., Hemsley, D., \& Smith, A. (1991). The neuropsychology of schizophrenia. Behavioral and Brain Sciences, 14, $1-84$

Hager, W., \& Hasselhorn, M. (Hrsg.) (1994). Handbuch deutschsprachiger Wortnormen. Göttingen: Hogrefe.

Harnishfeger, K. K., \& Bjorklund, D. F. (1994). A developmental perspective on individual differences in inhibition. Learning and Individual Differences, 6, 331-335.

Heil, M., Rösler, F., \& Hennighausen, E. (1996). Topographically distinct cortical activation in episodic long-term memory: The retrieval of spatial versus verbal information. Memory and Cognition, 24, 777-795.

Hemsley, D. (1993). A simple (simplistic?) cognitive model for schizophrenia, Behavior Research Therapy, 31, 622-645.

Jones, S. H., Gray, J. A., \& Hemsley, D. R. (1992). Loss of the Kamin blocking effect in acute but not chronic schizophrenics. Biological Psychiatry, 32, 739-755.

Kay, S. R. (1982). Conceptual disorder in schizophrenia as a function of encoding orientation. The Journal of Nervous and Mental Disease, 170, $154-163$.

Kayser, J., Bruder, G., Friedman, D., Tenke, X., Clar, A. S., Malaspina, D., \& Gorman, J. (1997). Brain event-related potentials (ERPs) in schizophrenia during a word recognition memory task. Psychophysiology, 34 (Suppl. 1), S52.

Kinsbourne, M., \& Winocur, G. (1980). Response competition and inter- ference effects in paired associate learning by Korsakoff amnesics. Neuropsychologia, 18, 541-548.

Knight, R. A. (1984). Converging models of cognitive deficit in schizophrenia. In W. D. Spaulding \& J. K. Cole (Eds.), Theories of schizophrenia and psychosis. Nebraska symposium on motivation (pp. 93156). Lincoln/London: University of Nebraska Press.

Koh, S. D. (1978). Remembering of verbal materials by schizophrenic young adults. In S. Schwarts (Ed.), Language and cognition in schizophrenia (pp. 55-99). Hillsdale, NJ: Erlbaum.

Lubow, R. E. (1989). Latent inhibition and conditioned attention theory. New York: Cambridge University Press.

Lubow, R. E. (1997). Latent inhibition as a measure of learned inattention: Some problems and solutions. Behavioural Brain Research, 188, 75-78.

Lukoff, D., Nuechterlein, K., \& Ventura, J. (1986). Appendix A. Manual for Expanded Brief Psychiatric Rating Scale (BPRS). Schizophrenia Bulletin, 12, 594-602.

McDowd, J. M., Filion, D. L., Harris, M. J., \& Braff, L. D. (1993). Sensory gating and inhibitory function in late life schizophrenia. Schizophrenia Bulletin, 19, 733-746.

McKenna, P. J., Tamlyn, D., Lund, C. E., Mortimer, A. M., Hammond, S., \& Baddeley, A. D. (1990). Amnesic syndrome in schizophrenia. Psychological Medicine, 20, 967-972.

Naumann, E. (1985). Ereigniskorrelierte Potentiale und Gedächtnis. Frankfurt, Germany: Peter Lang Verlag.

Nestor, P. G., Faux, S. F., McCarley, R. W., Penhume, G., Shenton, M. E., Pollak, S., \& Sands, S.F. (1992). Attentional cues in chronic schizophrenia: Abnormal disengagement of attention. Journal of Abnormal Psychology, 101, 682-689.

O'Carroll, R. E. (1995). Associate learning in acutely ill and recovered schizophrenic patients. Schizophrenia Research, 15, 299-301.

O'Carroll, R. E., Dunan, J., Murray, C., Austin, M., Ebmeier, K., \& Goodwin, G. (1993). Proactive interference and the neuropsychology of schizophrenia. British Journal of Psychology, 32, 353-356.

Oldfield, R. (1971). The assessment and analysis of handedness: The Edinburgh Questionnaire. Neuropsychologia, 9, 97-113.

Overall, J. E., \& Gorham, D. R. (1962). The Brief Psychiatric Rating Scale. Psychological Reports, 10, 419-427.

Pfefferbaum, A., Ford, J. M., White, P. M., \& Roth, W. T. (1989). P3 in schizophrenia is affected by stimulus modality, response requirements, medication status, and negative symptoms. Archives of General Psychiatry, 46, 1035-1044.

Postman, L., \& Underwood, B. J. (1973). Critical issues in interference theory. Memory and Cognition, 1, 19-40.

Pritchard, W. S. (1986). Cognitive event-related potential correlates in schizophrenia. Schizophrenia Bulletin, 100, 43-66.

Randolph, C., Gold, J. M., Carpenter, C. J., Goldberg, T. E., \& Weinberger, D. R. (1992). Journal of Clinical and Experimental Neuropsychology, $14,785-800$

Rösler, F., Heil, M., \& Röder, B. (1997). Slow negative brain potentials as reflections of specific modular resources of cognition. Biological Psychology, 45, 109-141.

Roth, W. T., Goodale, J., \& Pfefferbaum, A. (1991). Auditory event-related potentials and electrodermal activity in medicated and unmedicated schizophrenics. Biological Psychiatry, 29, 585-599.

Rugg, M. D. (1995). Event-related potential studies of human memory. In M. S. Gazzaniga (Ed.), The cognitive neurosciences (pp. 789-801). Cambridge, MA: MIT Press.

Rugg, M. D., \& Doyle, M. C. (1994). Event-related potentials and stimulus repetition in indirect and direct tests of memory. In H. Heinze, T Münte, \& G. R. Mangun (Eds.), Cognitive electrophysiology (pp. 124148). Cambridge, MA: Birkhäuser Boston.

Rugg, M. D., Doyle, M. C., \& Holstock, J. S. (1994). Modulation of event-related brain potentials by word repetition: Effects of local context. Psychophysiology, 31, 447-459.

Rugg, M. D., Mark, R. E., Gilchrist, J., \& Roberts, R. C. (1997). ERP repetition effect in indirect and direct tasks: Effects of age and interitem lag. Psychophysiology, 34, 572-586.

Ruoff, A. (1981). Häufigkeitswörterbuch gesprochener Sprache. Tübingen: Niemeyer.

Salo, R., Robertson, L. C., \& Nordahl, T. E. (1996). Normal sustained effects of selective attention are absent in schizophrenic patients withdrawn from medication. Psychiatry Research, 62, 121-130.

Saykin, A. J., Gur, R. C., Gur, R. E., Mozley, P. D., Mozley, L. H., Resnick, S. M., Kester, D. B., \& Stafiniak, P. (1991). Neuropsychological function in schizophrenia. Archives of General Psychiatry, 48, 618-624. 
Saykin, A. J., Shtasel, D. L., Gur, R. E., Kester, D. B., Mozley, L. H., Stafiniak, P., \& Gur, R. C. (1994). Neuropsychological deficits in neuroleptic naive patients with first-episode schizophrenia. Archives of General Psychiatry, 51, 124-131.

Schacter, D. L. (1987). Memory, amnesia, and frontal lobe dysfunction. Psychobiology, 15, 21-36.

Schmidt, K. -H., \& Metzler, P. (1992). WST-Wortschatztest. Weinheim: Beltz.

Shimamura, A. P. (1995). Memory and frontal lobe function. In M. Gazzaniga (Ed.), The cognitive neurosciences (pp.803-813). Cambridge, MA: The MIT Press.

Spitzer, M. (1997). A cognitive neuroscience view of schizophrenic thought disorder. Schizophrenia Bulletin, 23, 29-50.

Spitzer, M., Weisker, I., Winter, M., Maier, S., Hermle, L., \& Maher, B. A. (1994). Semantic and phonological priming in schizophrenia. Journal of Abnormal Psychology, 103, 485-494.

Tulving, E., Kapur, S., Craik, F. I., Moscovitch, M., \& Houle, S. (1994). Hemispheric encoding/retrieval asymmetry in episodic memory: Positron emission tomography findings. Proceedings of the National Academy of Sciences USA, 91, 2016-2020.

Uhl, F., Franzen, P., Serles, W., Lang, W., Lindinger, G., \& Deecke, L. (1990). Anterior frontal cortex and the effect of proactive interference in paired associate learning: A DC potential study. Journal of Cognitive Neuroscience, 2, 373-382.

Uhl, F., Podreka, I., \& Deecke, L. (1994). Anterior frontal cortex and the effect of proactive interference in paired associate learning-Results of brain-SPECT. Neuropsychologia, 32, 241-247.

Verleger, R. (1988). Event-related potentials and memory: A critique of the context updating hypothesis and an alternative interpretation of P3. Behavioral and Brain Sciences, 11, 343-427.

Wagner, M. (1997). Negatives Priming und selektive Aufmerksamkeit. Unpublished manuscript, University of Konstanz, Habilitationsschrift.

Wheeler, M. A., Stuss, D. T., \& Tulving, E. (1997). Toward a theory of episodic memory: The frontal lobes and autonoetic consciousness. Psychological Bulletin, 121, 331-354.

Williams, L. (1996). Cognitive inhibition and schizophrenic symptom subgroups. Schizophrenia Bulletin, 22, 139-151.

Wing, J. K., Cooper, J. E., \& Sartorius, N. (1974). Measurement and classification of psychiatric symptoms. London: Cambridge University Press.

Winocur, G., \& Weiskrantz, L. (1976). An investigation of paired-associate learning in amnesic patients. Neuropsychologica, 14, 97-110.

Zacks, R. T., \& Hasher, L. (1994). Directed ignoring: Inhibitory regulation of working memory. In D. Dagenbach \& T. H. Carr (Eds.), Inhibition processes in attention, memory and language (pp. 241-263). New York: Academic Press.

(Received November 25, 1997; AcCePted August 27, 1998) 